\title{
The Innovation Canvas as a Teaching Tool in Capstone Design: A Reverse- Engineering Case Study
}

\author{
Dr. Renee D. Rogge, Rose-Hulman Institute of Technology
}

Renee Rogge is the Samuel F. Hulbert Chair of Biomedical Engineering and Associate Professor of Biomedical Engineering at Rose-Hulman Institute of Technology. She has been teaching at Rose-Hulman since 2004, and her research interests lie in the areas of assessment of engineering design and orthopaedic biomechanics.

\section{Dr. Glen A. Livesay, Rose-Hulman Institute of Technology}

Glen Livesay is a Professor of Applied Biology and Biomedical Engineering; he co-developed and coteaches the biomedical engineering capstone design sequence at Rose-Hulman Institute of Technology. Glen's educational research interests include student learning styles, the statistical evaluation of assessment instruments, and increasing student engagement with hands-on activities. He has received an NSF CAREER award and served as a Fellow at the National Effective Teaching Institute.

\section{Dr. Jameel Ahmed, Rose-Hulman Institute of Technology}

Jameel Ahmed is Associate Professor and Head of the Department of Biology and Biomedical Engineering at Rose-Hulman Institute of Technology. He has been teaching at Rose-Hulman since 1999, and his technical interests lie in the areas of quantitative physiology and neuroprosthetics. He also has interest in helping develop leadership skills in others, as is evidenced by his involvement in Rose-Hulman's Leadership Advancement Program, and the Making Academic Change Happen (MACH) workshop. - See more at: http://www.asee.org/public/conferences/32/papers/9914/authors/23796\#sthash.3MCXSOY3.dpuf

\section{Dr. William A. Kline, Rose-Hulman Institute of Technology}

Bill Kline is Professor of Engineering Management at Rose-Hulman. He joined Rose-Hulman in 2001 and his teaching and professional interests include systems engineering, design, quality, innovation, and entrepreneurship.

Prior to joining Rose-Hulman, his industry experience includes roles as cofounder and Chief Operating Officer at Montronix and development manager at Kennametal.

Bill is a Phi Beta Kappa graduate of Illinois College and a Bronze Tablet graduate of University of Illinois at Urbana Champaign where he received a Ph.D. degree in Mechanical Engineering.

\section{Dr. Robert M. Bunch, Rose-Hulman Institute of Technology}

Dr. Michael Wollowski, Rose-Hulman Institute of Technology

Michael Wollowski obtained his undergraduate degree in Informatics from the University of Hamburg, Germany. He obtained M.S. and Ph.D. degrees in Computer Science from Indiana University in Bloomington, IN, USA. He studied under Jon Barwise and as part of his dissertation developed a diagrammatic proof system for planning in the blocks world of Artificial Intelligence. Michael is an associate professor at Rose-Hulman Institute of Technology in Terre Haute, IN, USA where he teaches introductory and advanced courses in the Computer Science and Software Engineering Department. Prior to that, he was a visiting assistant professor in the Computer Science department at Siena College in Loudonville, NY, USA. 


\title{
The Innovation Canvas as a Teaching Tool in Capstone Design: A Reverse-Engineering Case Study
}

\begin{abstract}
The design process is often perceived by students as a sequential or structured process even though design instructors try to focus attention on the iterative decisions, tradeoffs, and complexities associated with successful product, process, or service development. The Innovation Canvas was developed with the intent of more closely representing the process as it occurs in practice - a complex integration of design, business, and market themes. As an educational tool, the Innovation Canvas provides opportunities for design teams to organize, communicate, refine, and reflect on ideas and decisions in an integrated and linked framework.

A prototype version of the Innovation Canvas was introduced to thirteen biomedical engineering design teams (40 students) during a regularly scheduled capstone design lab to observe and evaluate novice student interactions with the material. Due to the complexity of the Innovation Canvas and lack of experience with using it in the classroom, the instructors chose to introduce it in the context of a reverse engineering activity. After completing the reverse engineering activity, the student teams explored the Innovation Canvas in terms of new product development. This paper will introduce the Innovation Canvas, discuss its implementation as a teaching tool in design, and present formative assessment results for the activity.
\end{abstract}

\section{What is the Innovation Canvas?}

The Innovation Canvas (IC) ${ }^{1,2}$ is a solution-development framework (shared under a Creative Commons ${ }^{3}$ license) that guides teams through the design process by merging themes from product design, business, and marketing in a way that more closely represents the process as it occurs in practice. ${ }^{4-7}$ In addition, it may provide design educators with an assessment tool for student learning as it provides an opportunity to compare initial, mid, and final versions of the IC during the course of a capstone design project. The IC may also help design teams focus attention on critical issues that can determine the success of a new design and to recognize the interconnection and overlap between the various technical and non-technical issues related to successful product development. Another potential strength of the IC for use in a capstone design course is the "at-a-glance" view of the critical components that must be considered, evaluated, and revisited during product development - the structure and interaction with the IC makes it difficult for students to ignore the "iterative" nature of the design process.

The IC supports a large number of design tools, methods, and approaches for implementation, such as Voice of the Customer, TRIZ (Theory of Inventive Problem Solving), Taguchi Methods, etc. Details regarding suggested tools and methods that may be incorporated into the IC, as well as other fundamental IC development components were presented by Kline et al. ${ }^{1}$ The intent of this paper is to provide formative feedback for future IC implementation and to investigate its potential as a teaching/assessment tool for capstone design instructors. 


\section{Layout of the Innovation Canvas}

The IC (Figure 1) is arranged in four quadrants surrounding a central theme of Value. Creating value is the primary objective of most design projects or ventures; therefore it takes "center stage" on the IC. The "value proposition" is a statement that describes how something of value is provided to customers/stakeholders (i.e. describing the need that the proposed solution is going to meet) and is often a primary measure of success. It should be noted that the concept of value has a very broad meaning and includes financial, societal, cultural, environmental, sustainability, and ethical valuations. The Value component of the IC is critical for design students as it puts their work in perspective - they must understand that products, services, and processes are not developed in a vacuum, but as a result of a complex and important evaluation of value to customers/stakeholders.

The four quadrants surrounding the central theme of Value are Explore, Ideate, Market, and Design.

The Explore quadrant provides opportunities for the design team to expand on concepts or opportunities for product or service development. The idea may still be emerging and design teams can utilize Voice of the Customer and Market Feedback knowledge to allow the new venture to take shape with discussion. For example, customer stories and scenarios may be obtained and discussed to develop a clearer picture of the market/need. In general, the Explore quadrant requires that a design team become better acquainted with the reality of the current (or potential) market.

The key themes in the Ideate quadrant are inspired by common design process themes and a model-based systems engineering approach. In the Ideate quadrant, the design team focuses on "what" the product should do, but not "how" it will be accomplished. The design team must consider the key functions of the system, the external systems that it interacts with, and the key features that will be marketed to the customer. The functions and features are the basic building blocks of the design process, while considering external systems helps the team to reveal the inputs, outputs, and interfaces of the system that are required to satisfy the customer stories and scenarios collected in the Explore quadrant.

The key themes in the Design quadrant are also inspired by common design process themes and a model-based systems engineering approach. Design teams are asked to consider the key components and modules of the product, the factors that are critical to product success, and the critical risk factors for this product. The design team must discuss "how" the product will meet the needs (implement the functions identified as necessary in the Ideate quadrant) and a final concept is selected and realized in components or modules. The step of mapping of functions to components can illustrate concepts of modular and integral designs.

In the Market quadrant, the focus is on the business model for the venture and the information entered here directly feeds back to the other three quadrants. It should be noted that for new products, all themes in the market quadrant would be relevant. However, for a smaller design project, all themes may not be relevant but should be carefully considered. 


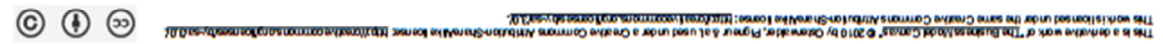

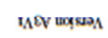

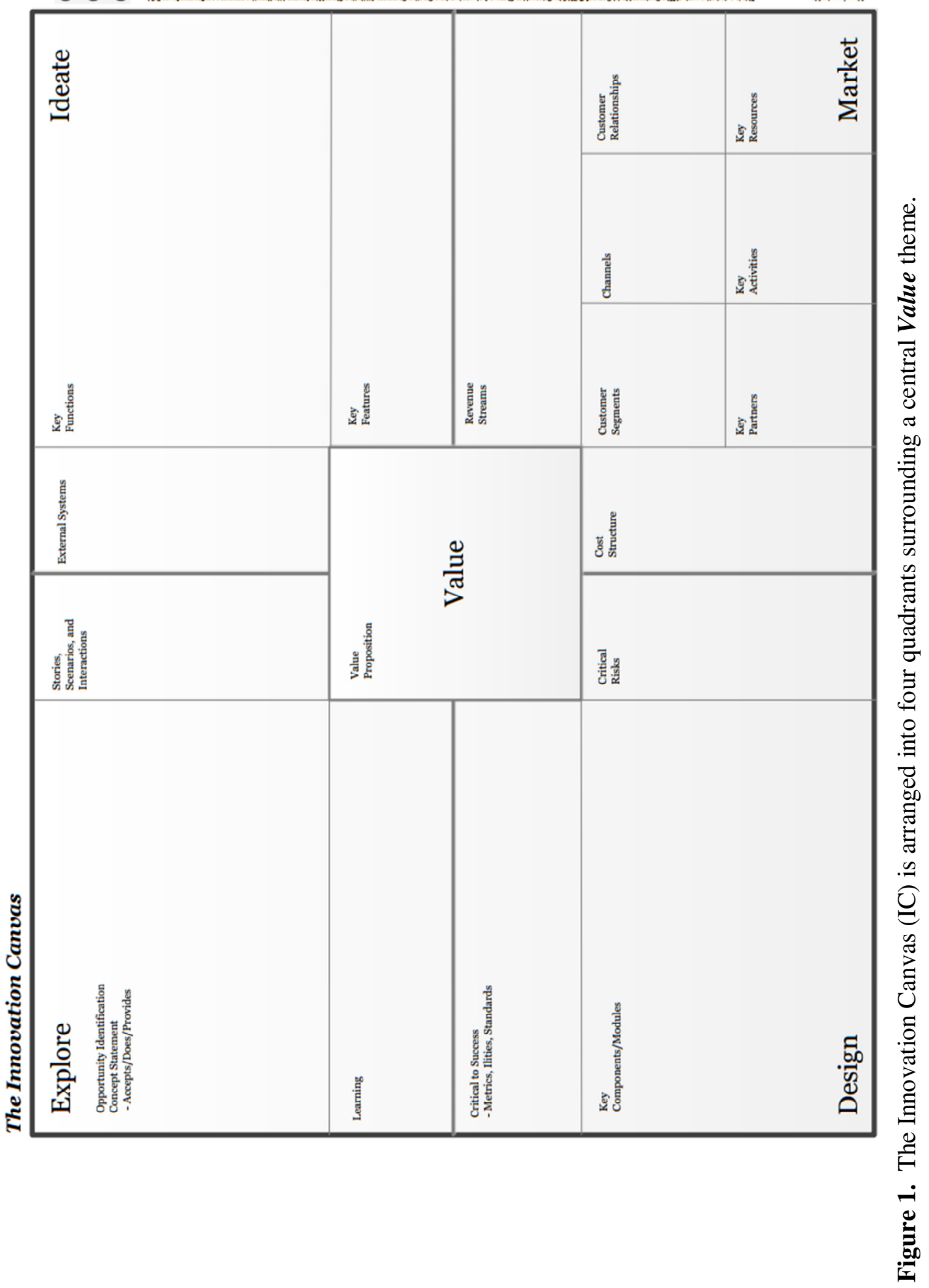

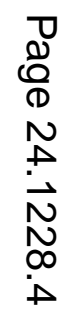




\section{Methods of Implementation for the Innovation Canvas}

To use the IC, a team interacts with a large, poster-sized version of the IC (Figure 1) and populates it with Post-It ${ }^{\circledR}$ notes that contain relevant information associated with the central Value theme and then each of the associated quadrants. The process is engaging, team-oriented, and encourages revision and alignment of the content across the IC. Depending on the experience level of the instructor and/or the design teams with the IC, the instructor may either directly suggest a process for using the IC or allow teams to explore the IC independently. The IC is ideally suited to support the capstone design experience by providing critical market and business contexts to design projects. ${ }^{8-10}$ The rest of this paper provides information on introducing the IC to capstone design students using a reverse engineering activity.

\section{Reverse Engineering of an Oral-B ${ }^{\circledR}$ Electric Toothbrush}

Reverse engineering (product dissection) is a well-established "hands-on" teaching technique where a student learns how a product functions by breaking it down into fundamental components. ${ }^{11-14}$ The combination of intellectual inquiry and physical activity helps to anchor knowledge and identify relationships between engineering fundamentals and functional design. The product dissection also provides an opportunity for design recovery, an activity with the goal of recovering the design processes that went into creating the product. ${ }^{11-13}$ The IC was implemented as a tool to help students thoroughly explore the design process and stimulate ideas for new product development.

During the Fall of 2013, forty senior Biomedical Engineers were introduced to the IC while dissecting an Oral- $\mathrm{B}^{\circledR}$ Complete Action electric toothbrush (Figure 2) during a regularly scheduled threehour lab period. The product dissection activity had been conducted in previous years, so the reverse engineering activity was wellestablished and familiar to the instructors. However, the IC was a new addition to the activity. Due to the complexity of the IC and the concern that it might overwhelm the students, the instructors chose to introduce it during the product dissection so the students could engage directly with the IC using a "staged" approach. Twelve groups of students were created (3 to 4 students per team) and each group was provided with an intact, functioning Oral-B® Complete Action Electric toothbrush.

Student teams were asked to investigate the toothbrush and complete the worksheet (developed by the course instructors) shown in Figure 3, without taking the device apart. Teams discussed the intended audience for the device, identified potential design criteria and critical features, and sketched potential mechanisms for the function of the device. After the teams completed the worksheet and discussed potential mechanisms with one of the instructors, the teams were allowed to disassemble the toothbrush and investigate the mechanisms. The total time spent on this portion of the activity was approximately 50 minutes. 


\section{Design $D_{i}{ }^{\mathrm{S}} \mathbf{s e}_{\mathrm{t}} \mathrm{C}_{\mathrm{i}} \mathrm{m}$ !}

The world is full of interesting designs, and you may have encountered products that made you think "What were they thinking?" or "I wonder why they did that?", etc. Of course, unless we specifically talk with the design team that develops a device, the best we can do is try to determine from the device itself what design decisions might have led to its development. Guess what! Being able to reverse a design to understand requires a solid understanding of the design process, but you're certainly up to the task! (but remember, you should only use this power for good .... not evil)

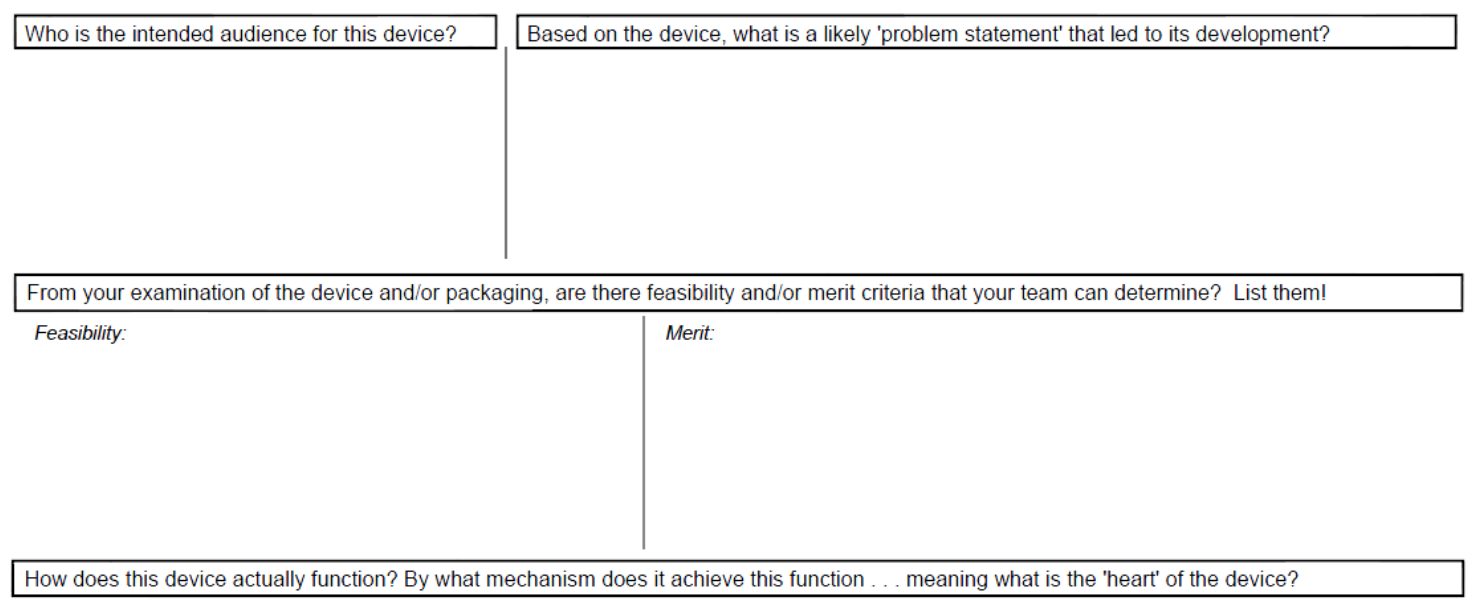

\section{Design Dissection (continued)}

Please sketch a circuit diagram for this device (hint: there's a battery and a motor):

Mechanically, how is the 'rotation' at the bristles achieved? That is, how is the rotation of a shaft (driven by a motor) turned into 'rotation'? Please sketch a potential mechanism

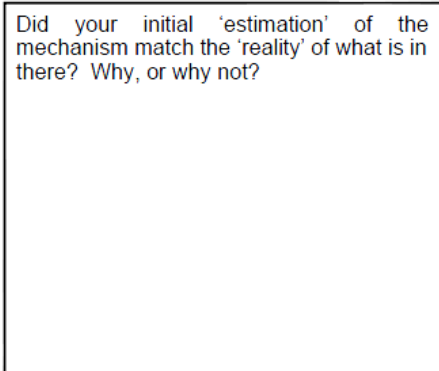

Figure 3. Worksheets used during the reverse engineering activity. The worksheets were completed prior to disassembly of the toothbrush. 
During the "wrap-up" discussion for the reverse engineering activity, several market, business, and design related questions were posed to the student teams. From the number and quality of the responses, it was clear that the students were not as comfortable with the marketing and business aspects of the product development process as they were with the "functional" aspects of the design. However, the students also understood that the "functional" component of the design was based on a market need that was communicated to the toothbrush designers. The Innovation Canvas was presented to the students as a tool that could help them build both technical and entrepreneurship skills in product development.

Each team was provided with a blank, poster-sized copy of the IC. Due to the complexity of the IC and the lack of background provided to the students regarding the quadrant themes (the students had not seen the IC prior to this activity), the instructors took approximately 1 hour and led the student teams through the IC activity as a group. The IC was presented as follows to the capstone design students:

1. Value: The students were prompted to develop a Value Proposition for the Oral-B® Complete Action toothbrush that was given to each group, i.e. "For (target customer) who (statement of the need/opportunity) our product is (product category) that (statement of benefit)."

Each group then shared their value proposition and the class discussed the similarities and differences between the Value Propositions. The student teams were encouraged to modify and expand their Value Proposition based on the discussion.

Sample responses:

"For adults who want to improve or maintain their oral hygiene our product is a toothbrush that will remove more plaque than the competition's toothbrush."

"For adults who want clean teeth our product is a personal hygiene product that prevents cavities and gingivitis."

\section{Ideate quadrant}

External Systems: In their groups, the students identified a few external systems for the current product. The students were provided with "Interfaces" as a prompt and immediately identified "teeth" as an external system. The students brainstormed and then shared their ideas with the class.

Sample responses:

"teeth, water, mouth, hand, counter, toothpaste"

"teeth, hands, gums, tongue, water, toothpaste, toothbrush holder, counter, cheeks, food" 
Key Features/Functions: In their groups, the students identified a few functions (i.e. accept user input, have replaceable heads) of the current product. The students brainstormed and then shared their ideas with the class. A key concept that students investigated and discussed was that a marketing group may identify the features needed to make a device attractive to a target group of customers. As device designers, they must ensure the device has the necessary functionality to deliver these features.

Sample responses:

"cleans teeth, easy to use, turns on/off, can change the battery, replaceable brush head"

"accepts user input, safe, has a removable battery, keeps water out of critical components"

Functional Decomposition: A sample functional decomposition for the electric toothbrush was provided to the class and discussed to illustrate the concepts and identify areas for creative design solutions (Figure 4). Note: This task is much easier to do for a reverse engineered product, since the product is available for evaluation and the solution is already known. Completing a functional decomposition for a new product is often challenging, but it is an important step to aid in concept generation. ${ }^{15-17}$

\section{Design quadrant}

Key Components/Critical to Success: The students identified components and subsystems that were critical to the current design. This information tied directly to the aspects of the design that were critical to the success of the design. The teams were also prompted to brainstorm various metrics that could be used to evaluate the success of the design (e.g. evaluating manufacturing costs, providing statistical evidence of improved performance, etc.)

Sample responses:

"design of head for optimal bristle motion; simple design improves manufacturability, waterproof housing, easy switch implementation"

"cleanable, changeable head/battery, multiple color options" 

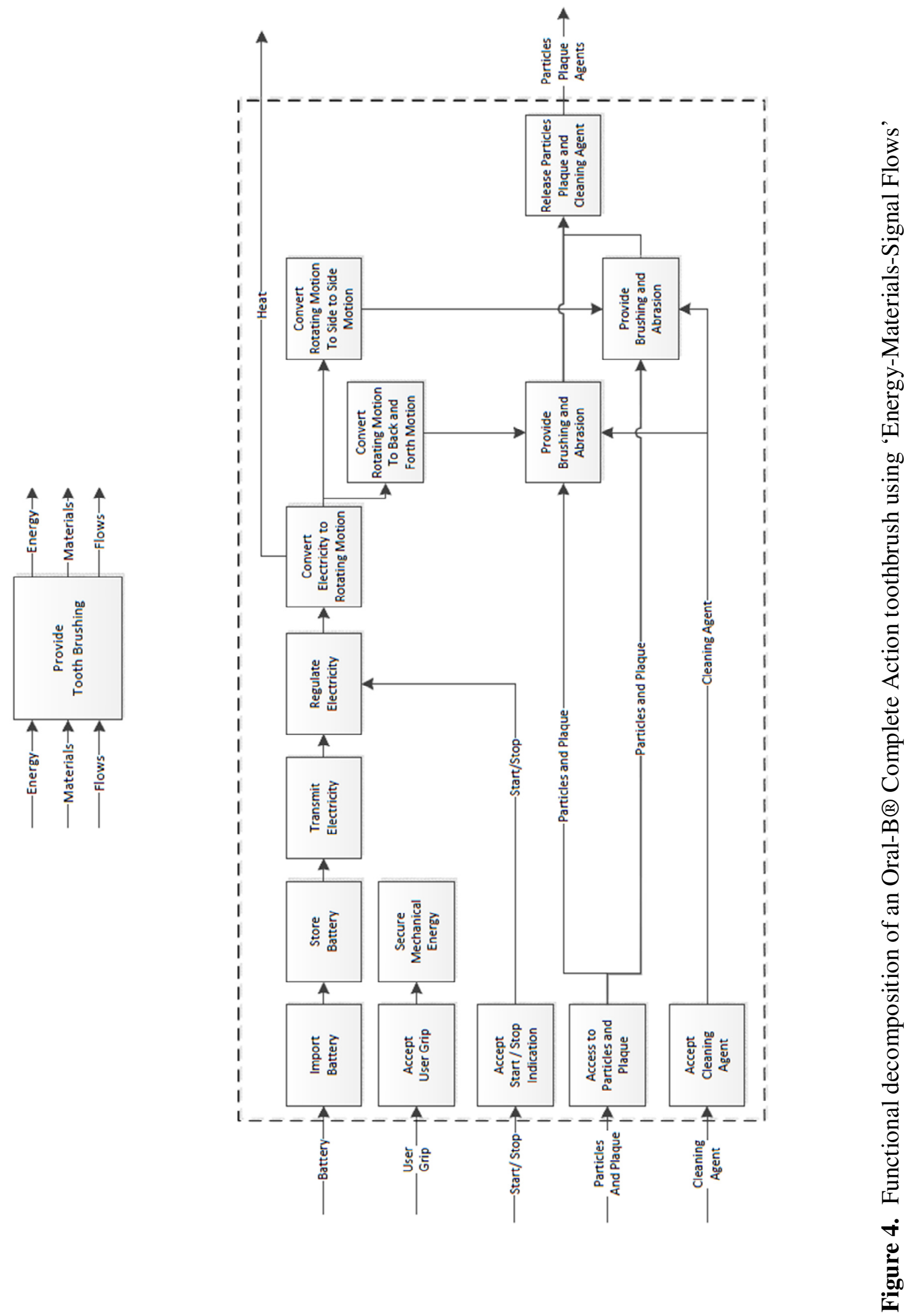


\section{Explore quadrant}

At this point in the activity, the students were asked to move into a "new product development" mindset using the IC. For the "Explore" aspect of the IC, the students were asked to identify some opportunities for developing a "revolutionary" product for maintaining dental hygiene. The students discussed "Voice of the Customer" and "Opportunity Assessment" and developed several ideas for new products to meet a variety of needs.

Sample responses:

"Quiet, comfortable for hand and mouth, replaceable/rechargeable battery, tongue cleaner, force sensor (so you don't push too hard)"

"timer function, tongue cleaner, toothpaste/mouthwash dispenser"

\section{Market quadrant}

The discussions in the Explore quadrant led very naturally to Market considerations and provided an opportunity for student teams to discuss and investigate a variety of market concerns for the product. At a minimum, considering revenue, cost, and target customers provides a basic introduction of market context into the design process. The discussion of target customer segments quickly leads to customer demographics, possible desirable features, and possible pricing. Similarly, discussion of cost structure leads to manufacturability and market size considerations.

Sample responses:

"Dental associations, vendors, ADA standards"

"Advertisers, dentists, celebrity endorsements, coupons

\section{Iterate!}

By the end of the activity, the information in the Explore and Market quadrants of the IC required changes to the "Value Proposition". Once the student teams modified the "Value Proposition", it became clear to them (after an instructor-led discussion) that the Ideate quadrant would change and a new design could be developed. Thus, the idea that new product development is an iterative process was illustrated quite clearly using the IC. 
A "post-activity" survey was conducted with the capstone design students who participated in the IC activity. The students were asked the following questions:

1. What aspects of the IC were the most helpful/insightful for you? Why?

2. What aspects of the design IC were the most confusing for you? Why?

The survey revealed some interesting findings regarding the most "helpful/insightful" aspects of the IC. Each aspect (Explore, Value, Ideate, Design, Market) was identified as being the most helpful/insightful by students in the class (Table 1). This was encouraging to the instructors because the IC was able to engage all the students during the reverse engineering activity and the survey results support the importance of implementing the IC in a team environment as each member brings a unique and important set of concerns and issues to the IC. Eleven students commented on the structure of the IC as being helpful for providing an overall perspective and making them think about the different aspects of design and all of the areas that need to be taken into account for product development. Students also commented on the freedom that the IC provides, i.e. they can start anywhere without a forced direction of implementation.

While six students identified the "Marketing" quadrant as helpful, twenty-five of their colleagues found the "Marketing" aspect to be the most confusing to complete. The students commented that they did not understand most of the marketing terms (revenue streams, cost structure, customer segments, channels, etc.) and did not feel as though they were well-informed on these topics and how they related to the design process (unlike the Explore, Ideate, and Design aspects). Many of the students commented that while they appreciated the importance of marketing in the engineering design process, marketing was "not interesting" to them. The instructors agreed with the students' assessment regarding the challenges of the "Marketing" aspects of the IC. The students struggled while completing the "Marketing" section of the IC and asked the instructors many more "what does this mean?" questions when they reached that part of the activity. It was also noted that the "Marketing" section of the IC had much more "white space" at the conclusion of the activity than any of the other sections. While numerous factors influence the success of a product, understanding the product market is clearly one of the primary indicators. ${ }^{18-19}$ Despite their discomfort with the marketing terminology and lack of expertise in this area, design students were able to identify the critical role that marketing and business context plays in product development. The IC was an effective tool for introducing marketing concepts and provided a foundation for future development of these concepts. 
Table 1. The number of students identifying quadrants of the IC as "most helpful" and/or "most confusing". Note that number of responses does not equal the number of students taking the survey as students could identify more than one helpful or confusing aspect.

\begin{tabular}{|c|c|c|}
\hline Quadrant & Most Helpful Aspects & Most Confusing Aspects \\
\hline Value & 6 & 4 \\
\hline Explore & 9 & 6 \\
\hline Ideate & 14 & 3 \\
\hline Design & 12 & 3 \\
\hline Market & 6 & 25 \\
\hline
\end{tabular}

\section{Conclusions \& Recommendations}

The Innovation Canvas was an interesting addition to the reverse engineering activity and was an engaging and active way to introduce the content of the IC (rather than through a traditional lecture). While more research is required to refine the content and delivery of the IC, it was encouraging to the design instructors that the students seemed to easily make connections to other design course content even if the terms used on the IC were slightly different. For example, the biomedical engineering students used the terms "merit" and "feasibility" while developing their decision matrix for their projects. The students readily translated these terms to "key features/functions" and "critical to success" metrics. It is hypothesized that this task may be more difficult for freshman or sophomore-level students, but it is an important skill to develop in graduating seniors as they head into careers where the terminology may be different, but the concepts are the same.

It was also informative to discover that students struggled more with the "Marketing" quadrant of the IC than the other aspects of the canvas. As marketing and business concepts are not a primary focus in this current capstone design course (or an area of expertise for the design instructors), this was not unexpected and indicates a need for faculty development in this area and targeted activities to assist students with these important concepts. While the authors believe that it is important to incorporate the marketing aspects of the IC into the context of senior design, capstone design instructors may need to tailor the "Marketing" quadrant to meet the educational objectives of the course. Other approaches to improve students' ability to handle the Marketing aspects of a design course might include requiring an Engineering Management or Business course directly related to marketing or having a larger portion of a design course devoted to these topics.

One of the most successful outcomes from this activity was the dynamic and interactive nature of the activity. The members of each team had to work together to clarify and understand the IC requirements. The instructors moved from team to team during the lab to provide encouragement, clarify instructions, and answer questions. While this may have biased the student work product, it positively impacted the classroom dynamics. Another important decision that may influence the outcome of the activity is the product chosen for dissection. The 
instructors chose the electric toothbrush since it was a product that was familiar to the students, it was easy to disassemble (required only a screwdriver), it had a clever mechanism at the brushhead for the students to investigate, and it required a relatively straight-forward functional decomposition diagram. While the IC fit well with this device, it will be important to try other products with the IC.

The reverse engineering activity was an interesting and interactive approach to introducing the IC and its content to capstone design students. Future work includes implementing the IC at various stages of the capstone design process to investigate its utility as a learning assessment tool.

\section{References}

1. Kline, W.A., Hixson, C.A., Mason, T.W., Brackin, M.P., Bunch, R.M., Dee KC, and Livesay, G.A. (2013) The Innovation Canvas-A Tool to Develop Integrated Product Designs and Business Models. Proceedings of the 2013 ASEE Annual Conference, Atlanta, GA, June 2013.

2. Innovation Canvas, http://www.rose-hulman.edu/offices-and-services/office-of-innovationengagement/innovation-canvas.aspx

3. About the Licenses. https://creativecommons.org/licenses/

4. Wagner, Tony. Creating Innovators, The Making of Young People Who Will Change the World. New York, Scribner, 2012.

5. Schoen, Jeremy, Thomas W. Mason, William A. Kline, and Robert M. Bunch. "The Innovation Cycle: A New Model and Case Study for the Invention to Innovation Process." Engineering Management Journal. Vol. 17, No. 3, September 2005.

6. Sheppard, S, Kelly Macatangay, Anne Colby, and William M Sullivan. Educating Engineers: Designing for the Future of the Field. San Francisco, CA: Jossey-Bass, 2009.

7. Atman, C.J., Adams, R. S., Cardella, M. E., Turns, J., Mosborg, S., and Saleem, J. J. (2007). Engineering Design Processes: A Comparison of Students and Expert Practitioners. Journal of Engineering Education, 96(4), $359-379$.

8. Liebenberg, Leon and E.H. Mathews. "Integrating innovation skills in an introductory engineering design-build course.” International Journal of Technology and Design Education 22(2012): 93-113.

9. Jarratt, T.A.W., Caldwell, N.H.M. and P.J. Clarkson. "Engineering change: an overview and perspective on the literature." Research in Engineering Design 22(2011): 103-124.

10. Johnson, M.D. and R. E. Kirchain. "The importance of product development cycle time and cost in the development of product families." Journal of Engineering Design 22(2011): 87-112.

11. McCracken, W.M. and W. Newstetter. Reverse Engineering or Design Recovery: Two approaches to uncovering designing. Proceedings of the American Society for Engineering Education (2000).

12. Otto, K.N. and K.L. Wood. "Product evolution: a reverse engineering and redesign methodology." Research in Engineering Design 10(1998): 226-243.

13. Wood, K.L., Jensen, D, Bezdek, J, and K.N. Otto. "Reverse engineering and redesign: courses to incrementally and systematically teach design." Journal of Engineering Education 90(2001): 363-374. 
14. Dalrymple, Odesma, David A Sears, Demetra Evangelou. "The Motivational and Transfer Potential of Disassemble/Analyze/Assemble Activities.” Journal of Engineering Education. 11(4), pp. 741-759, 2011.

15. George E. Dieter, Engineering Design: A Materials and Processing Approach, Kevin T. Kane, Ed.: McGrawHill, 2000.

16. David G. Ullman, The Mechanical Design Process, 3rd ed., Bill Stenquist, Ed.: McGraw-Hill, 2003.

17. Karl T. Ulrich and Steven D. Eppinger, Product Design and Development.: McGraw-Hill, 2000.

18. Barr, R., Schmidt, P., Krueger, T. and C.Y. Twu. An Introduction to Engineering through an Integrated Reverse Engineering and Design Graphics Project, J of Engineering Education, 89(4), pp. 413-418, 2000.

19. Saunders, M.N., Seepersad, C.C., and Katja Holtta-Otto. "The Characteristics of Innovative, Mechanical Products." J Mech Des, 133(2011): 1-9. 